\title{
The Factors affecting Breast Milk and Supplementary Nutrition Practices: A Survey Study
}

\author{
Dogan $\mathbf{A}^{1}$, Dag $\mathbf{H}^{1}$, Gedik $\mathbf{H}^{2 \star}$, Pismisoglu $\mathbf{K}^{\mathbf{1}}$, Oztepeli $\mathbf{R}^{\mathbf{1}}$ and Arica $\mathbf{V}^{\mathbf{1}}$ \\ ${ }^{\prime}$ Department of Pediatrics, Health Sciences University, Okmeydani Training and Research Hospital, Istanbul, Turkey \\ ${ }^{2}$ Department of Infectious Diseases and Clinical Microbiology, Ministry of Health Bakirkoy Sadi Konuk Training and Research Hospital, \\ Istanbul, Turkey
}

\section{Article Info \\ *Corresponding author: \\ Habip Gedik \\ Associate Professor \\ Department of Infectious Diseases and \\ Clinical Microbiology \\ Ministry of Health Bakirkoy Sadi Konuk \\ Training and Research Hospital \\ Istanbul, Turkey \\ Tel: +902124145309 \\ Fax: +902124147508 \\ E-mail: habipgedik@yahoo.com}

\section{Received: July 20, 2018 \\ Accepted: August 4, 2018 \\ Published: August 9, 2018}

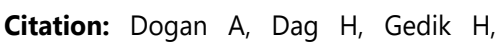
Pismisoglu K, Oztepeli R, Arica V. The Factors affecting Breast Milk and Supplementary Nutrition Practices: A Survey Study. Madridge J Vaccines. 2018; 2(1): 54-56.

doi: $10.18689 / \mathrm{mjv}-1000111$

Copyright: (c) 2018 The Author(s). This work is licensed under a Creative Commons Attribution 4.0 International License, which permits unrestricted use, distribution, and reproduction in any medium, provided the original work is properly cited.

Published by Madridge Publishers

\begin{abstract}
Objective: The purpose is to investigate the factors related to child and family that influence the breastfeeding practice.
\end{abstract}

Materials and Methods: In this survey study, a 20-question survey was conducted the parents whose infants were between 10 and 18 months of age and admitted to the department of pediatrics at Ministry of Health Okmeydani Training and Research Hospital between September 15, 2013 to September 15, 2014.

Results: In the study, 56 infants who were between 10 and 18 months old were included. The mean age was $13.4 \pm 0.2$ months (Range: 8 - 18 months) and $32(57 \%)$ were male. At the first hour of birth, 14 (30\%) infants received breast milk, followed by 24 (42\%) infants who received between 1 and 2 hours, and $18(28 \%)$ infants who received after 2 hours. The mean time to start supplementary foods was $4.9 \pm 0.1$ months and the time to start supplementary foods were first month in 4 infants (7.1\%), 2- 5 months in 14 (25\%) infants, $5-7$ months in 29 (51.7\%) infants, and later than seven months in $9(16 \%)$ infants.

Conclusion: It is seen that maternal knowledge level and practices about breast feeding are high among our surveyors, but not optimal. It is thought that the mothers should be educated in terms of beginning of breast-feeding immediately after the birth, and giving only breast milk without supplementary food in the first four months, and that should be reminded during the visits to the outpatient clinic.

Keywords: Breastfeeding; Family; Education; Supplementary food.

\section{Introduction}

World Health Organization (WHO) recommends only breast feeding to infants during the first six months and then continued with the mother with supplementary foods [1]. However, breast-feeding rates were reported to be from $57 \%$ to $91 \%$ in different countries, but in the fourth month only breast-feeding rates remain to be 25 $46 \%[2,3]$. In our country, infants receive supplementary food in the early moths and the number of infants fed with breast milk in the first six months is not much as it is expected $[4,5]$. A few factors, such as maternal age, education, smoking status, socio economic status, have been found to be effective on breast feeding and infant feeding practices in developing and developed countries $[2,6,7]$. It was reported that younger and less educated mothers provided less time to feed their baby with breast milk, and cow milk, was found to be given earlier than it is recommended $[3,5,7,8]$. Smoking mothers also found that they gave less breast milk to their babies $[5,7]$. 
During the infancy, the content of diet and the duration of breastfeeding affect the incidence and complications of infectious diseases. In a study including 21,000 infants from China, it was found that the prevalence of pneumonia and diarrhea in infants who received only breast feeding in the first four month were less than those of children who did not receive breast feeding [9].

The purpose of this study is to investigate the factors related to child and family that influence the breastfeeding practice.

\section{Materials and Methods}

In this survey study, a 20-question survey was conducted the parents whose infants were between 10 and 18 months of age and admitted to the department of pediatrics at Ministry of Health Okmeydani Training and Research Hospital between September 15, 2013 to September 15, 2014. The study was conducted in the mothers whose infants were treated in the pediatric clinic as being inpatient without any chronic disease. After the written and verbal information about the study, the consent form was signed by parents. The questionnaire contained questions about the status and duration of breast feeding in the first year of life, the time to feed with supplementary food, the educational status of the mother, and the socio economic level of the family. The income level of the families is less than 2 times, $2-5$ times and 5 times higher than the minimum wage amount. Infants with chronic diseases (chronic lung disease, cholestasis, recurrent urinary tract infections, cerebral palsy, metabolic disease, malabsorption) and preterm delivery were not included in the study.

Statistical analysis was performed by SPSS (Statistical Package of Social Science) Software 11.0.Standard descriptive statistical methods were used. Patients' ages were described as range, median and mean \pm standard deviation. Calculated percentages of variables were described with decimals. Fisher's chi-square test was used when the chi-square test was used to compare the group ratios and t-test was used to compare the mean \pm standard deviation of two groups. Pearson correlation test was used to find the correlation between variables. Statistical significance was defined as p-value was less than 0.05 .

\section{Results}

In the study, 56 infants who were between 10 and 18 months old were included. The mean age was $13.4 \pm 0.2$ months (Range: 8 - 18 months) and 32 (57\%) were male. At the first hour of birth, 14 (30\%) infants received breast milk, followed by 24 (42\%) infants who received between 1 and 2 hours, and 18 (28\%) infants who received after 2 hours. The late check out from operation room was the most common reported reason related to the delay of breast feeding, followed by the respiratory problem of baby. The mean time to start supplementary foods was $4.9 \pm 0.1$ months and the time to start supplementary foods were first month in 4 infants (7.1\%), 2 - 5 months in 14 (25\%) infants, 5 - 7 months in $29(51.7 \%)$ infants, and later than seven months in $9(16 \%)$ infants. The reasons for starting supplementary food in the first 4 months were that the doctor recommended, as the baby could not gain weight (4 babies) and mother thought that the baby had a lot of appetite and was not sated with breast milk (14 babies).

The first supplementary foods were revealed to be formula in 30 infants (53.5\%), vegetable soup in infants (7.1\%), cow milk in 3 infants (5.3\%), yoghurt in 8 infants (14.2\%), fruit juice in 5 infants, 9), and biscuits in 7 infants (12.5\%). Mother responded to use mixer while making supplementary foods of $30(53.5 \%)$ babies. The mean time to start giving the first cow milk was $9.8 \pm 0.3$ months (Range: $2-18$ months) and 39 (69.6\%) of the infants were receiving cow milk as supplementary food. In the question about the educational status of the parents, 16 mothers reported that they were primary / secondary school graduates, followed by 28 mothers of high school graduates and 12 mothers of university graduates.

The distribution of families according to monthly income was 4 families $(7.1 \%)$ with less than $1000 \mathrm{TL}, 24$ families (42.8\%) with 1000-2000 TL, 21 families (37.5\%) with 3000$5000 \mathrm{TL}$, and 7 families (12.5\%) with $\geq 5000 \mathrm{TL}$.

There was no significant relationship between the economic income of the family and mother's educational status and the mother's first supplementary food start time, only breast feeding period, cow milk feeding behavior ( $p$ > $0,05)$. As the mother's age increased, it was found to be started later on cow milk feeding ( $r: 0,467, p=0,001)$, and other parameters did not differ in different age groups ( $p>$ $0.05)$. Forty-six (82.1\%) of the parents said that getting professional support positively contributed to the feeding of infants.

\section{Discussion}

All of the participating mothers started to breast feed their babies within the first 24 hours, and as 30\% of the mother started to breast feeding in first hour after the birth. It seems that parents are aware of the importance of mothering. According to the most recent data in our country, $83 \%$ of newborn babies started to suckle [8]. Although 18 mothers reported to start supplementary food in the first four months, the mean supplementary food starting time was 4.9 months. In a study conducted in Diyarbakir, a city of Turkey, $40 \%$ of infants started to receive solid food before forth month [9]. Although doctors inform mothers, the idea that babies are not sufficiently satisfied and that they cannot gain weight causes the additional nutrient transition time to be four months earlier. It is known that mothers with low socio economic level are more likely to have a sense of weight gain by competing with the weight and development of the other children in their surroundings, and by having the environment influence them $[8,9]$. Mothers have been revealed to start breast feeding immediately after birth and to give food supplementation other than breast milk by the proposition of doctors and nurses in many studies [10-14]. Moreover, in a 
study in Pakistan, it has been reported that this training contributes to the development and infant feeding and less diarrhea cases if the baby is started in the prenatal period [15]. In our study, $82 \%$ of the mothers stated that getting professional support positively contributed to the feeding of babies. A lack of skills or training and too little time among physician were reported to be barriers for providing breast feeding care [16]. It is obvious that especially pediatricians should support mothers about breast feeding in the first six months.

In our study, there was no difference in terms of the income level of the family and the educational status of the mother and the breast feeding practices with supplementary food. In a survey of low-economic regions in Vietnam, a positive correlation was found between maternal education level and maternal breast feeding rate [17]. The difference in the practice of infant feeding is likely to be due to the income levels of the families and the fact that the infants are taken to the pediatrician by regular checks.

As a result, it is seen that maternal knowledge level and practices about breast feeding are high among our surveyors, but not optimal. It is thought that the mothers should be educated in terms of beginning of breast-feeding immediately after the birth, and giving only breast milk without supplementary food in the first four months, and that should be reminded during the visits to the outpatient clinic. The transition to supplementary food after breast feeding and the application of its content should also be included in that training.

\section{References}

1. World Health Organization. Global strategy for infant and young child feeding. The optimal duration of exclusive breastfeeding. A54/INF. DOC./4.1 2001

2. Giovannini $M$, Riva $E$, Banderali $G$, et al. Feeding practices of infants through the first year of life in Italy. Acta Pcediatr. 2004; 93(4): 492-497.

3. Simic $T$, Glamuzina DS, Boranic $M$, Vuksic I, Boban A. Breastfeeding practices in Mostar, Bosnia and Her- zegovina: Cross-sectional self-report study. Croat Med J. 2004; 45(1): 38-43.
4. Lande $B$, Andersen LF, Bærug $A$, et al. Infant feeding practices and associated factors in the first six months of life: The Norwegian Infant Nutrition Survey. Acta Pcediatr. 2003; 92(2): 152-161.

5. Lanting $\mathrm{Cl}$, Wouwe JP, Reijneveld SA. Infant milk feeding practices in the Netherlands and associated factors. Acta Pcediatr. 2005; 94: 935-942. doi: 10.1080/08035250510036723

6. Kakute PN, Ngum J, Mitchell P, et al. Cultural barriers to exclusive breastfeeding by mothers in a rural area of Cameroon, Africa. J Midwifery Womens Health. 2005; 50: 324-328. doi: 10.1016/j.jmwh.2005.01.005

7. Wamani H, Astrom AN, Peterson S, Tylleskar T, Tumwine JK. Infant and young child feeding in western Uganda: Knowledge, practices and socioeconomic correlates. J Trop Pediatr. 2005; 51: 356-361. doi: 10.1093/ tropej/fmi048

8. Yigit EK, Tezcan S. Feeding habits of babies, nutritional status of children and mothers. Turkey Demographic Health Survey. 2003; 141-155.

9. Ozelci PE, Elmaci N, Ertem M, Saka G. Belief and practices in relation to breast feeding among migrant mothers in slums of Diyarbakır, Turkey 2001. Eur J Public Health. 2006; 16: 143-148. doi: 10.1093/eurpub/cki170

10. Wang $X$, Wang $Y$, Kang $C$. Feeding practices in 105 counties of rural China. Child Care Health Dev. 2005; 31(4): 417-423. doi: 10.1111/j.1365-2214.2005.00523.x

11. Ummarino $M$, Albano $F$, De Marco $G$, et al. Short duration of breastfeeding and early introduction of cow's milk as a result of mothers' low level education. Acta Pediatr Suppl. 2003; 92(s441): 12-17. doi: 10.1111/j.1651-2227.2003. tb00641.x

12. Theofilogiannakou $M$, Skouroliakou $M$, Gounaris $A$, Panagiotakos $D$, Markantonis SL. Breast-feeding in Athens, Greece: Factors associated with its initiation and duration. J Pediatr Gastroenterol Nutr. 2006; 43(3): 379384. doi: 10.1097/01.mpg.0000228104.97078.bb

13. Labarere J, Gelbert-Baudino N, Ayral AS, et al. Efficacy of breastfeeding support provided by trained clinicians during an early, routine, preventive visit: a prospective, randomized, open trial of 226 mother-infant pairs. Pediatrics. 2005; 115(2): 139-146. doi: 10.1542/peds.2004-1362

14. Coutinho SB, de Lira PIC, Lima MC, Ashworth A. Comparison of the effect of two systems for the promotion of exclusive breastfeeding. Lancet. 2005; 366(9491): 1094-1100. doi: 10.1016/S0140-6736(05)67421-1

15. Saleemi MA, Zaman $\mathrm{S}$, Akhtar $\mathrm{HZ}$, et al. Feeding patterns, diarrhoeal illness and linear growth in 0-24-month- old children. J Trop Pediatr. 2004; 50(3): 164-169. doi: 10.1093/tropej/50.3.164

16. Taveras EM, Li R, Grummer-Strawn L, Richardson M, Marshall R, Rego $\mathrm{VH}$, et al. Opinions andpractices of clinicians associated with continuation of exclusive breastfeeding. Pediatrics. 2004; 113(4): 283-290.

17. Duong DV, Binns CW, Lee AH. Breast-feeding initiation and exclusive breast-feeding in rural Vietnam. Public Health Nutr. 2004; 7(6): 795-799. 